\title{
REFERENCES
}

Skinner D. V., Camm A. J. \& Miles S. (1985) Cardiopulmonary resuscitation skills of preregistration house officers. British Medical fournal 290, 1549-50.

Wynne G., Marteau T. M., Johnston M., Whiteley C. A. \& Evans T. R. (1987) Inability of trained nurses to perform basic life support. British Medical fournal 294, 1198-99.

\section{Splenic injuries}

\section{Sir}

We would like to add our comments to the articles on splenic injuries by Chambers \& Pilbrow and by McLaughlan et al. (Archives of Emergency Medicine 5, 26-37). This department has had for some time a policy or referring all stable post-traumatic patients with abdominal symptoms and/or signs for abdominal ultrasound examination.

During 1987, 26 patients were referred for abdominal ultrasound examination. Their mean age was 36 years (range 12-88 years). None of these patients had a systolic blood pressure lower than $100 \mathrm{~mm} \mathrm{Hg}$. Only three patients had a pulse rate faster than 110 beats per minute. All had abdominal tenderness, bowel sounds were present in all but two of the patients and none complained of shoulder tip pain. Six of the patients had fractured lower ribs and three had a pneumothorax. Abdominal ultrasound examination was performed within $2 \mathrm{~h}$ of the patients ariving in the accident and emergenco

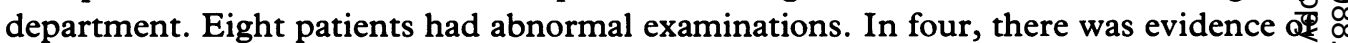
free fluid in the peritoneal cavity, three had splenic tears, two renal damage and one patient had a lacerated liver. Some of the patients had more than one abnormality? Subsequently, two patients required a laparotomy confirming a liver tear in one and a shattered spleen in the other. All patients with abnormal scans were admitted for observation. Further ultrasound examinations at a later stage were performed which showed non progression or resolution of splenic or renal haematoma. Of the 18 patients with normal ultrasound examinations, 10 were discharged home, as we felt confiden that they had no intra-abdominal complications. None of these patients returned. The remaining eight patients were admitted because of other serious injuries. None required laparotomies.

Our observation agree with those of McLauchlan et al. (1988) in that patients with intra-abdominal injuries may initially have only non-specific findings. A high degree of suspicion is required in order not to miss an abdominal injury. Same as Chambers \& Pilbrow (1988) we find abdominal ultrasound to be a useful tool for screening such patients. We have been able to safely discharge stable patients with upper abdominal tendernes and a normal ultrasound examination rather than admitting them for observation, thus relieving pressure on surgical beds and saving finances.

M. REICHL, T. WOOD \& R. A. SLEET

Accident and Emergency Department,

Southampton General Hospital,

Tremona Road,

Southampton, England 